\title{
Defining the climatic signal in stream salinity trends using the Interdecadal Pacific Oscillation and its rate of change
}

\author{
V. H. McNeil ${ }^{1}$ and M. E. Cox ${ }^{2}$ \\ ${ }^{1}$ Resource Sciences and Knowledge, Department of Natural Resources and Water, Brisbane, Qld, Australia \\ ${ }^{2}$ School of Natural Resource Sciences, Queensland University of Technology, Brisbane, Qld, Australia
}

Received: 27 March 2006 - Published in Hydrol. Earth Syst. Sci. Discuss.: 20 September 2006

Revised: 13 March 2007 - Accepted: 23 March 2007 - Published: 3 May 2007

\begin{abstract}
The impact of landuse on stream salinity is currently difficult to separate from the effect of climate, as the decadal scale climatic cycles in groundwater and stream hydrology have similar wavelengths to the landuse pattern. These hydrological cycles determine the stream salinity through accumulation or release of salt in the landscape. Widespread patterns apparent in stream salinity are discussed, and a link is demonstrated between stream salinity, groundwater levels and global climatic indicators. The Interdecadal Pacific Oscillation (IPO) has previously been investigated as a contributory climatic indicator for hydrological and related time series in the Southern Hemisphere. This study presents an approach which explores the rate of change in the IPO, in addition to its value, to define an indicator for the climate component of ambient shallow groundwater levels and corresponding stream salinity. Composite time series of groundwater level and stream salinity are compiled using an extensive but irregular database covering a wide geographical area. These are modelled with respect to the IPO and its rate of change to derive control time series. A example is given of how a stream salinity trend changes when the decadal climatic influence is removed.
\end{abstract}

\section{Introduction}

This work arose originally from the recognition of patterns in stream salinity on a regional basis. Variations or trends in salinity represented by Electrical Conductivity (EC) can be significant and have often been measured as a potential indicator of landuse sustainability issues. These issues include the incipient development of dryland salinity, impacts of land clearing, irrigation, drainage alterations, and urbanisation (for instance, Ruprecht and Schofield, 1991). EC

Correspondence to: V. H. McNeil

(mcneilv@nrm.qld.gov.au) monitoring is relatively low cost and convenient to automate. However, it can only be relied on to define long-term human impact if such impacts can be distinguished from variations that result from broad climate fluctuations.

A control site is needed which has the same climate characteristics but without the local landuse effect. However, particularly for large catchments, comparable undisturbed sites may not be available. The likelihood of a consistent pattern in the climate effect over a large area offers the possibility of developing a composite climate control by aggregating EC data widely and using global climate indicators to verify that the broadscale pattern is, in fact, a climate signal.

Accordingly, the purpose of this study is to verify that decadal scale climatic trends are present in records of Queensland stream salinity and its associated groundwater hydrology by relating the records to global climatic indicators.

1.1 Recognition of broadscale decadal patterns in stream salinity trends

The influence of climatic fluctuations on stream salinity was recognised in a previous study (QDPI, 1994) where EC trends were calculated for around 500 stream gauging stations throughout the state of Queensland covering a twenty year period between 1970 and 1990, in a project to investigate the impact of changes in landuse. It was expected at the time that the climatic contribution would present as local random noise overlying longer-term trends representative of local landuse changes.

Instead of the expected generally flat EC trends with rises or crests in areas where rapid development had occurred, a complex but consistent trend pattern was evident in many streams, over a very diverse range of topography, geology and landuse. Some examples from the 1994 study are shown on Fig. 1. It can be seen that many of the streams had relatively low ECs during the early 1970s, followed by a steady

Published by Copernicus GmbH on behalf of the European Geosciences Union. 


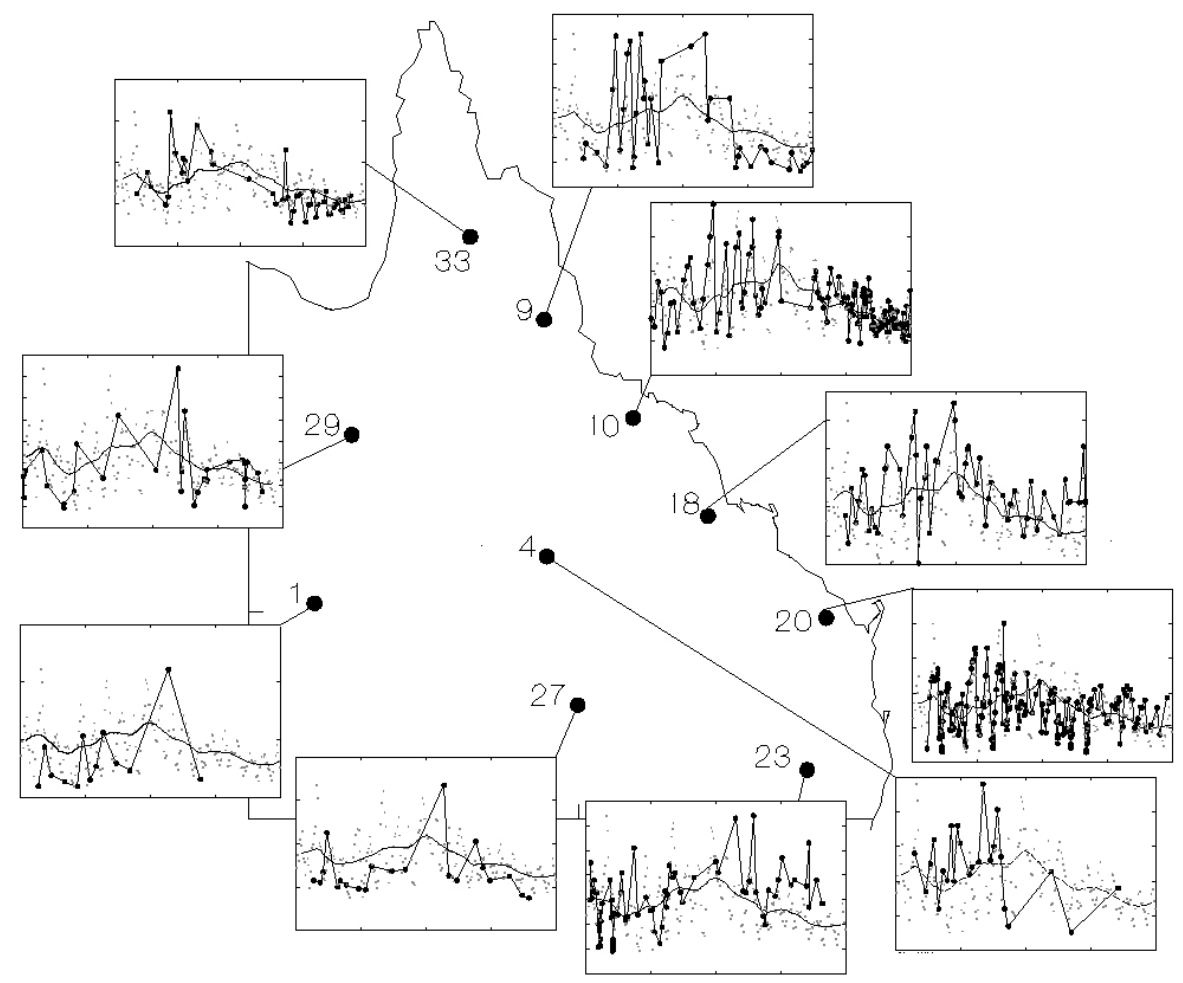

Fig. 1. Measured stream ECs 1970-1990 at selected sites (points and zig-zag lines). Smooth trace is modelled climatic component of EC for Queensland. Climate component scaled vertically to a spread comparable with field values. Note similarities in character of field EC across geography, especially EC elevated around 1980.

rise until about 1980. After this there was a general decline, which left 1990 salinity levels lower than those of 1970 over most of the State. Note that Queensland encompasses a considerable land area; the state extends from $9^{\circ} \mathrm{S}$ to $29^{\circ} \mathrm{S}$ in latitude, from $138^{\circ} \mathrm{E}$ to $154^{\circ} \mathrm{E}$ in longitude, and occupies most of the northeast quadrant of Australia.

Subsequent work (McNeil and Cox, 2002) investigated similar broadscale patterns in shallow unconfined groundwater levels. The details are given below. It was conceptually reasonable that the medium and long-term patterns in ground and surface water interaction would be affected by prevailing climatic trends as well as landuse.

Climate effects on stream EC are complex because they involve rainfall and temperature patterns, and the dynamic interactions between ground and surface water (McNeil et al., 2005). Intense or prolonged wet conditions would flush accumulated salts from the surface and from upper soil horizons, resulting initially in large flows of dilute surface water. The wet conditions also recharge the groundwater, as shown by level A on Fig. 2, leading to a greater groundwater contribution to streams over the next few drier years (shown as level B). Groundwater, being generally more saline than overland flow from prolonged contact with weathering minerals, raises the average salinity of streams in this phase. If the dry period continues, the groundwater contribution declines as groundwater levels drop below the streambeds (level C on Fig. 2), a feature typical of Queensland alluvial aquifers. This causes the streams to become more ephemeral, runoff dominated, and consequently less saline. The declining salinity trend continues slowly until the next flood event, when there is again a sharp drop in EC followed by the subsequent rise. It should therefore be possible to define a control time series calculated from composite data from a large geographical area, and modelled on long-term climate variables to distinguish the underlying climate signal at a site from the landuse and local noise.

A clear link between climate and streamflow has been established and reported by a number of authors including Chiew et al. (1998) and Lough (1991). However, apart from Vaccaro (1993), who reported groundwater levels to be sensitive to climatic variability, and Evans et al. (2001), who related salt concentration in lakes to variation in the North Atlantic Oscillation (NAO), there have been few studies to date on the numerical relationship between decadal climate indicators and groundwater levels or surface water salinity.

\section{Consideration of potential climatic indicators}

The influence of climate on hydrology and subsequently stream salinity is not solely related to precipitation, because 
temperature and evapotranspiration affect runoff, soil moisture storage and ultimately groundwater levels (Chiew et al., 1998). Therefore a more general and geographically broadscale climate indicator is required than could be provided by local observations such as running means of rainfall.

The most significant general climate component is the El Nino/Southern Oscillation phenomenon (ENSO) which results from the interactions between large-scale oceanic and atmospheric circulation processes in the equatorial Pacific Ocean. ENSO can be characterised by indices based on variations in either barometric differences or Sea Surface Temperatures (SST). The most widely used barometric indicator is the Troup Southern Oscillation Index (SOI) (Troup, 1965). Some SST indicators are based on data recorded by the Tropical Atmospheric Ocean (TAO) array of moored buoys across the equatorial Pacific. They include Nino1 +2 covering $0^{\circ}$ to $10^{\circ} \mathrm{S}, 80^{\circ}$ to $90^{\circ} \mathrm{W}$; $\mathrm{Nino} 3\left(5^{\circ} \mathrm{S}\right.$ to $5^{\circ} \mathrm{N}, 150^{\circ} \mathrm{W}$ to $\left.90^{\circ} \mathrm{W}\right)$; Nino3.4 $\left(5^{\circ} \mathrm{S}\right.$ to $5^{\circ} \mathrm{N}, 170^{\circ} \mathrm{W}$ to $\left.120^{\circ} \mathrm{W}\right)$, and Nino4 $\left(5^{\circ} \mathrm{S}\right.$ to $5^{\circ} \mathrm{N}, 160^{\circ} \mathrm{W}$ to $\left.150^{\circ} \mathrm{W}\right)$.

ENSO has been linked to precipitation and streamflow throughout the world (e.g. Philander, 1990). In addition there are studies on many specific regions: USA (Gray, 1990; Kahya and Dracup, 1993; Zorn and Waylen, 1997); Peru (Henderson et al., 1990); New Zealand (Gordon, 1986; Mullan, 1995; McKerchar et al., 1996, 1998); Belgium (Gellens and Roulin, 1998) and western Africa (Gray, 1990). A number of authors including McBride and Nicholls (1983); Ropelewski and Halpert (1987, 1989); Lough (1991); and Chiew et al. (1998) have considered the effect of ENSO on Queensland's rainfall. Chiew et al. (1998) and Lough (1991) also established that, as in the case of rainfall, there was a clear link between Australian streamflow and ENSO. Lough (1991), Cordery et al. (1993), Burt and Shahgedanova (1998), and Power et al. (1999, 2005), however, have all observed that the relationship of ENSO with hydrology over time is definitely non-stationary. This leads to problems in fitting long-term hydrological time series based on ENSO indicators alone, indicating that its interaction with other global climatic influences should also be considered.

Other modes of climatic variability have been detected on decadal time scales that are controlled by SST anomaly patterns. These modes may be more aligned than the rapidly fluctuating ENSO to the longer term trends required to separate the climate signal from landuse in slowly varying, lag responsive natural systems. They have been identified through complex empirical orthogonal functions (CEOF) (Zhang et al., 1997; Rowell and Zwiers, 1999). CEOF is a statistical technique used to detect structure revealed by very slow decay of percent variance in noisy data.

The most significant climatic signals that have been identified to date by CEOF analysis of global SST data are a secular trend representing global warming (IPCC, 1996); the Pacific Decadal Oscillation (PDO) derived from analysis of monthly SST data over the extra-tropical North Pacific (Zhang et al. 1997); and the Inter-decadal Pacific Oscilla-

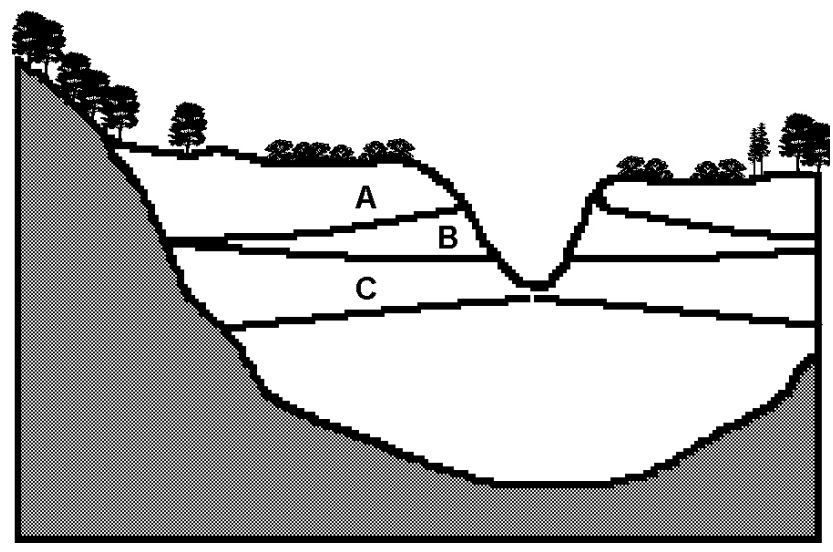

Fig. 2. Conceptual cross-section of alluvial valley showing typical groundwater levels:

- A: groundwater levels after prolonged or intense wet conditions, surface flushing and groundwater recharge - low salinity

- B: drying climate leads to lower runoff and greater groundwater contribution to stream flow - higher salinity

- C: as the dry spell continues, the groundwater levels tend to drop below stream beds - reversal of rising salinity trend.

tion (IPO) (Power et al., 1998, 1999; Folland et al., 1999, $2002 a, b)$. The IPO is based on near-global datasets and can be regarded as the Pacific-wide manifestation of the PDO. Similarities have been noted between the SOI and the IPO, although they were derived independently (Folland et al., 2002a, b).

The IPO has been proved to modulate ENSO climate variability in the Pacific region (Salinger et al., 2001; Power et al., 2005). In particular, during positive phases of the IPO (IPO $>0.5)$, El Nino events are noted to be more common, whereas La Niña events tend to occur more under the negative IPO phase $(\leq 0.5)$.

Recent studies (Kiem et al., 2002; Kiem and Franks, 2004; Franks, 2002; McKeon et al., 2004; Verdon, 2004; Jones and Everingham, 2005) have incorporated both the IPO and ENSO indicators such as SOI or Nino3 in their analyses of climatic effects on hydrology by dividing the IPO into positive, negative and neutral phases as recommended by Power et al. (1999), and modelling the likelihood of events on ENSO separately within each phase. However, a more continuous indicator was required to analyse the effect of climate, as a single process, on patterns in an historical time series. It was also decided that a simple climatic indicator would be desirable to model the effect on stream salinity and groundwater levels. It is expected that reasonable correlations based on a simple model would be more robust than a more complex model with greater skill. 


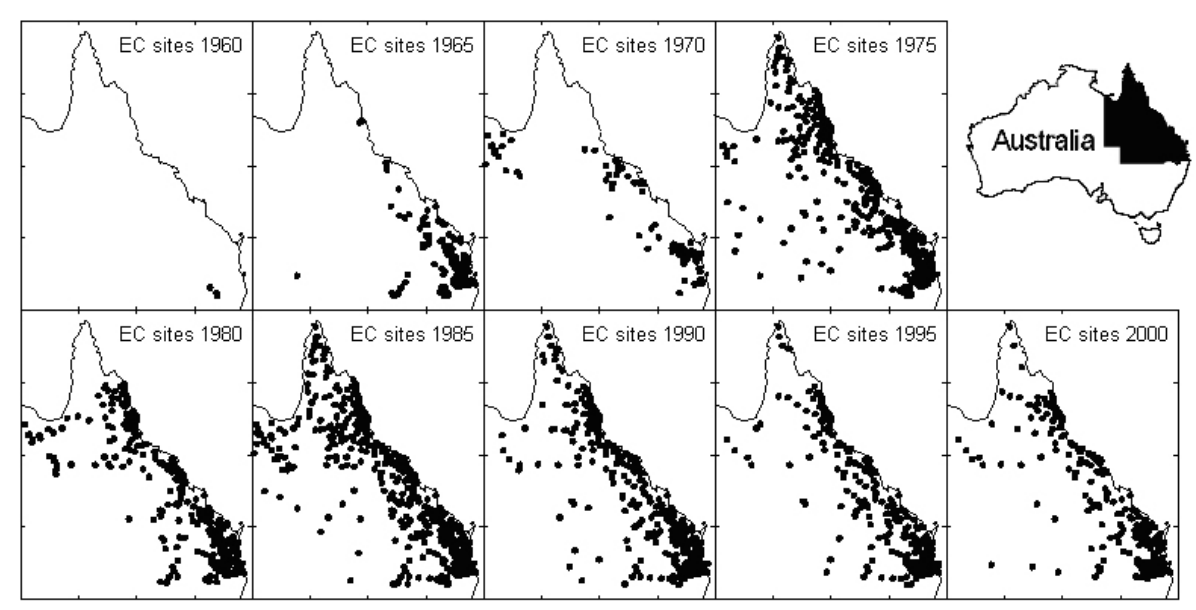

Fig. 3. Distribution of EC samples stored in the NRW database representing Queensland, over the 40 year period from 1960 to 2000.

\section{Deriving composite time series to represent broad- scale trends in EC and groundwater levels}

\subsection{Data used in the study}

The data used in this study are from the water quality and hydrological databases held by the Queensland Department of Natural Resources and Water (NRW). Although these data are variable in content, reliability and periodicity of sampling, it was expected that these shortcomings would be evened out by the use of monthly medians covering all of Queensland. The surface water quality database contains nearly 50000 EC measurements, collected from 815 gauging stations with the earliest records beginning in 1962 in the south-east. The average number of samples per site is around 70, collected irregularly but usually four times a year. The groundwater data base contains approximately 500000 individual water level (WL) measurements from over 30000 bores, most of which were only sampled once or twice, usually when first drilled. Although shallow groundwater is used throughout the state, the great majority of bores are concentrated in irrigated alluvial plains which have mostly been cleared and developed. Because the bores are particularly concentrated within irrigation areas, it is recognised that there may be some bias from pumping or regional depression, or rises due to deforestation, overwatering, or disturbance to natural drainage patterns.

\subsection{Preparing annual time series for EC and water levels}

Time series were produced for monthly medians of EC and groundwater levels. All non-artesian WL measurements no deeper than $30 \mathrm{~m}$, and all EC measurements taken at gauged sites within a particular month were included, regardless of location. Annual time series were based on climatic years (October of the preceding year till September) to avoid splitting the (Southern Hemisphere) summer wet season, as rec- ommended by Loewe and Radok (1948). Annual values were calculated if all months were represented for the climatic year. The arithmetic mean was used in the case of $\mathrm{WL}$, and the geometric mean in the case of EC, in line with their observed normal and lognormal distributions, respectively. Finally, a 3 year moving mean (geometric mean for the EC) was used to produce series in which seasonal variation was smoothed and the impact of irregularity and outliers minimised.

This exercise produced an almost continuous annual time series for EC since 1963, and WL since about 1950, but not all years were considered to be sufficiently representative for use in constructing the climatic model. The composite time series contained only years with a reasonably comprehensive and consistent coverage of the state, and at least 100 measurements in the case of EC, and 1000 in the case of groundwater. Figure 3 summarises the distribution of EC measurement sites in Queensland over the period of record. The representative period for modelling was taken as 1968-2002 for EC, and 1968-2001 for WL. It is accepted that the distribution of gauging stations shown on Fig. 3 indicates that the EC time series would be most representative of the coastal and central regions. However, the similarity of the pattern with that observed throughout the state in QDPI (1994) indicates that it is general enough for a preliminary study aimed at verifying a climatic influence on the decadal trends observed. The WL pattern resembled plots prepared by Jolly and Chin (1991) for bores in undisturbed areas of the Northern Territory to the west of Queensland which have been monitored since the 1950s.

Once the composite WL and EC time series had been derived, it was necessary to verify that they contained a significant broadscale decadal climatic signal. This process required the selection of suitable climatic indicators to compare with the composite time series. 

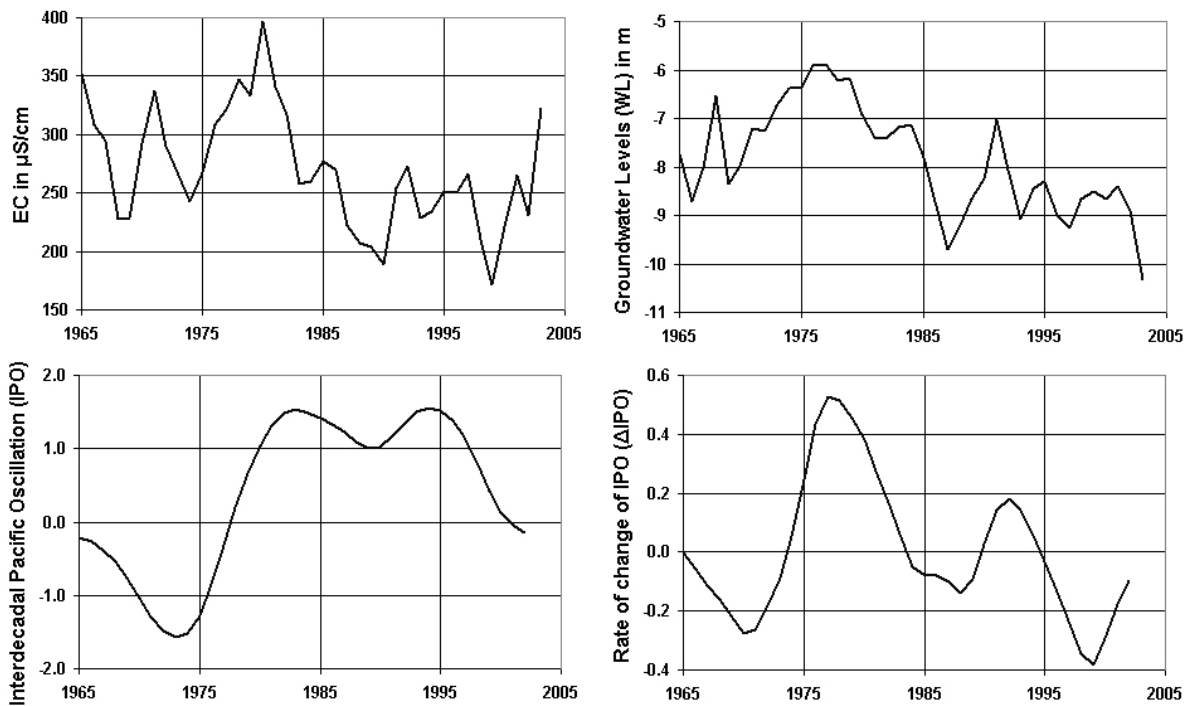

Fig. 4. Climatic variables IPO and $\triangle I P O$, and State-wide composite groundwater levels and stream salinity since 1965 , as used for the modelling.

\section{Modelling EC and water levels with the IPO and its rate of change}

\subsection{Choice of climate indicators}

It was considered from the work of previous authors mentioned above that the SOI was likely to show some covariance with the composite series because of its proven association with Queensland hydrology. Accordingly, the first approach taken was to correlate the composite series with the mean SOI for both the 12 months and the 6 months before the start of the wet season. Both linear and nonlinear regression techniques were examined, followed by repetition of the techniques using various transformations including lags, running means and Fourier transformations, but no significant correlations were found. It was also visually apparent that the SOI did not contain the longer periodicity apparent in the composite series, and that a smoothed decadal scale indicator would offer the best potential match.

It was following this that the IPO was tested, as it was regarded by authors such as Verdon et al. (2004) and Micevski et al. (2006) as being relevant to Queensland hydrological conditions. Again, neither linear nor non-linear regression produced a relationship between the raw IPO and the composite series, but when the IPO and the WL series were examined together, it was apparent that the groundwater levels did not reflect the actual value of the IPO, but rather the way in which it was changing at the time. Figure 4 displays these climatic indicators with the EC and WL time series. Despite the contentious nature of the IPO (Power et al., 2006), this approach is consistent with Verdon et al. (2004) and Micevski et al. (2006) who recognised that the hydrology of Queensland responds differently to the SOI when the IPO is in a positive or negative phase with respect to its mean.
Use of the rate of change of the IPO $(\Delta \mathrm{IPO})$ is a logical extension of this phase technique, and is simpler to apply when modelling a continuous series of historical data. The Nino3, Nino4 and Nino3.4 records are too short in relation to the composite series to be applied in models at this stage, although they may be tested as a more robust alternative in the future.

The January value of the slowly varying IPO was selected to represent the climatic year in the middle of the wet season, and the $\triangle$ IPO was taken as the forward difference between annual values. The reason for using the January IPO rather than a mean is that the rate of change could be calculated on non-transformed values, which was considered more desirable considering the level of understanding of the mechanisms underlying the IPO. It was considered that the rate of variation in both the IPO and the decadal-scale changes being modelled in the data were sufficiently gradual that the actual method of defining annual difference was not critical for this exploratory study.

To confirm the final selection of climatic indicators to model the WL and EC, a series of Principal Component Analyses (PCA) was run to compare the series with candidate indicators. The results of the final PCA including hydrology, salinity and the most correlated climatic variables are displayed on Fig. 5. The PCA indicated that while streamflow is correlated with the SOI and inversely correlated with the IPO, the WL and EC series do not correlate well with either SOI or IPO. However, the WL and to a lesser extent the EC were observed to have a reasonable correlation with $\triangle$ IPO. As a result of these observations, the IPO and its rate of change were selected from the several broadscale climatic indicators examined as being the most appropriate to derive decadal scale control series. 


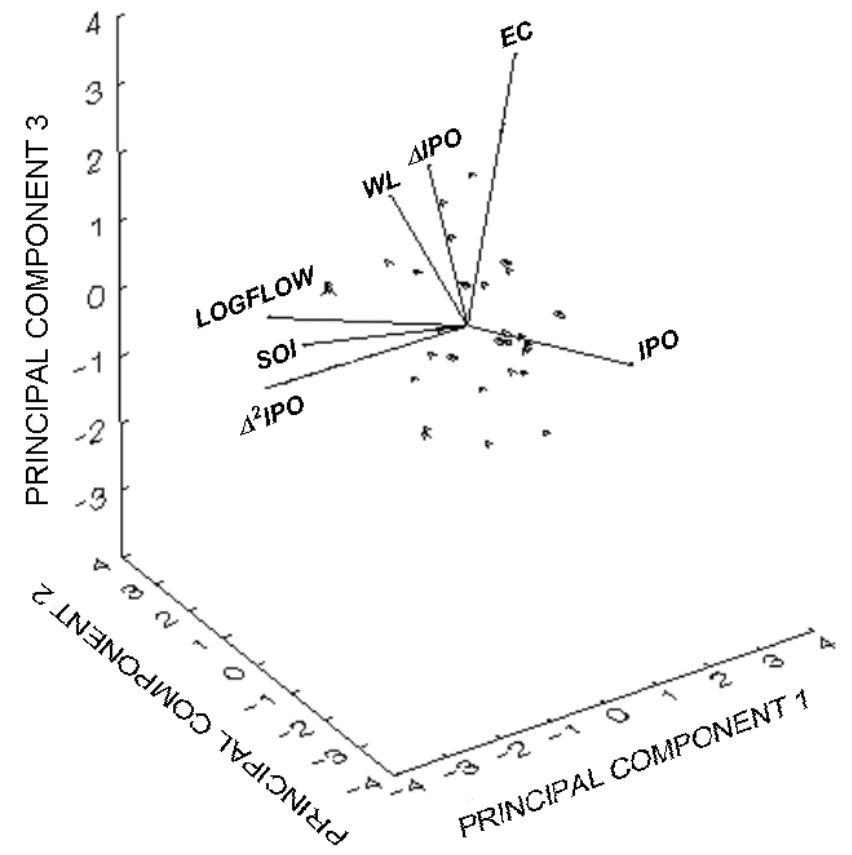

Fig. 5. Principal Component Analysis on annual composite field series and annual climate indicators. Note $\triangle I P O, W L$ and EC are grouped orthogonal to Flow and the rest.

It is accepted that the relationship between the IPO and hydrological processes is still poorly understood and contentious. Therefore it was decided to compare the $\triangle$ IPO with streamflow qualitatively before its final acceptance as a valid parameter for modelling the less direct relationships of WL and EC. The Burdekin River is one of the largest rivers in Queensland, and has a flow history extending back to the 1920s. It is also reasonably indicative of general hydrological conditions over a wide area of Queensland (Allan, 1985). To remove short term variability, annual flow in the Burdekin was smoothed by transformation to a three year geometric mean. This statistic is more resistant to outliers than the arithmetic mean, and therefore suitable for positively skewed hydrological data (Hirsch and Slack, 1984; McBean and Rovers, 1998). The transformed river flows were then examined in relation to the prevailing trends in the IPO as shown in Fig. 6.

Table 1 qualitatively describes the observed stream flow in relation to the behaviour of the IPO. Flows in the Burdekin tend to be above the median when the IPO is changing rapidly, particularly when it is rising. As the rate of change slows, flows diminish, and droughts are most common when the rate of change is close to static. This visual relationship was considered sufficiently in line with the other confirmations to trial the IPO and its rate of change as indicators for a simple model to test for climatic variability in WL and EC series.
On the basis of these results, modelling was carried out on the composite WL and EC time series solely on the basis of the IPO and its rate of change because, although introducing other parameters might produce a better fit, more complexity would increase the risk of over-fitting because of the very limited amount of data. It was decided to apply both linear and second order polynomial regressions, as nonlinearity in the relationship between climatic indicators and hydrological time series has been noted by other authors. Power et al. (2005), for example, point out that whereas the upper limits of hydrological events are not confined, lower limits are generally constrained.

\subsection{Groundwater levels}

Modelling of the WL time series was based on the 19682001 representative period. The first stage was a second order polynomial regression using the $\triangle \mathrm{IPO}$, which accounted for $50 \%$ of the total variance (Fig. 7). The equation is:

$\mathrm{WL}=4.1633 \Delta \mathrm{IPO}^{2}+2.0116 \Delta \mathrm{IPO}-8.1148$

The residuals from the first model were then plotted against the IPO to include the longer term trend. This produced the polynomial:

Residual WL $=0.42 \mathrm{IPO}^{2}-0.47 \mathrm{IPO}-0.3298$.

The final model of 3-year moving average groundwater levels for bores less than $30 \mathrm{~m}$ was therefore

$$
\begin{aligned}
\mathrm{WL}_{\mathrm{MODEL}}= & 0.42 \mathrm{IPO}^{2}-0.47 \mathrm{IPO}+4.1633 \Delta \mathrm{IPO}^{2} \\
& +2.0116 \Delta \mathrm{IPO}-8.4446
\end{aligned}
$$

The correlation coefficient of the model with the composite data, as shown on Fig. 8 was over $80 \%\left(R^{2}=0.81\right)$. The model was then extended to all years since 1958 to see how it compared with the more uncertain part of the groundwater level record. Figure 9 compares the model and the WL series over time, showing that the climate signal covers the main trends in the record.

\subsection{Stream EC levels}

Stream EC has a more complex relationship with climate than groundwater levels do because of its dependence on both ground and surface water processes. The modelled groundwater level (WL $\mathrm{WODEL}_{\text {) }}$ series is a partial climatic indicator for stream EC because of the groundwater contribution of salt to streams, as illustrated in Fig. 2. Whereas low ECs tend to occur during both high and low groundwater level phases, high ECs are only conceptually likely when the groundwater level is high but runoff is diminished (Fig. 2, Phase B). This bimodal behaviour is verified on Fig. 10, where the plot of EC versus WLMODEL shows that maximum

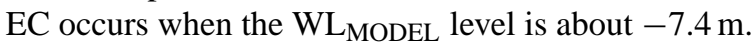

When accounting for the variability in EC due to groundwater levels as represented by $\mathrm{WL}_{\mathrm{MODEL}}$, it is difficult to 
Table 1. Predictability of decadal flow trends in the Burdekin River, based on behaviour of the IPO.

\begin{tabular}{lll}
\hline Decade & Behaviour of the IPO & Observed Burdekin flow regime \\
\hline $1920-1930$ & Rising, quite rapidly in mid years & At least median, above in mid years \\
$1930-1940$ & Fall then rise, but fairly static & Usually low, particularly in early years \\
$1940-1950$ & Falling rapidly & Above median \\
$1950-1960$ & Rising, rapidly in later years & Above median, particularly in later years \\
$1960-1970$ & Stationary, fall in later years & Very low, rising to median later \\
$1970-1980$ & Slow fall early, then very rapid rise & Low initially, then well above median \\
$1980-1990$ & Slowing rise then slow fall & Dropping and remaining below median \\
$1990-2000$ & Slow rise followed by rapid fall & Around median, driest in mid years \\
\hline
\end{tabular}

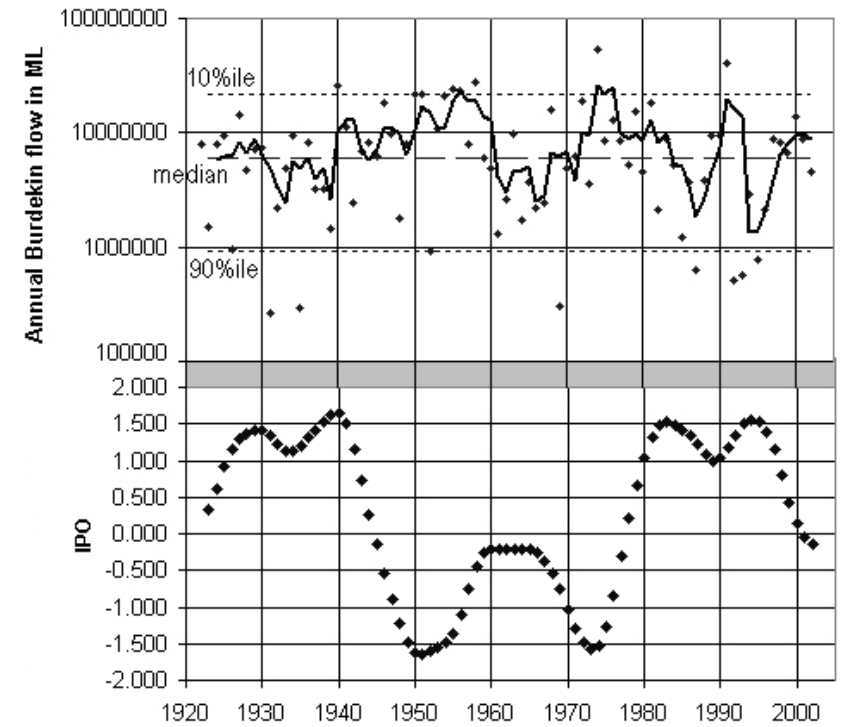

Fig. 6. Comparison of the long term IPO with recorded annual flows in the Burdekin River. Note the tendency for the IPO to go through a generally rising and falling phase on about a 50 year cycle, and the tendency for the river flow (most easily seen in the three-year moving geometric mean) to be above the median when the IPO is changing rapidly, particularly when the change is positive.

fit a single algorithm. It is also conceptually inappropriate because the variance in EC increases greatly at high groundwater levels where other processes involving surface flows dominate some of the time. Therefore the EC series was divided into two overlapping phases: high WL $\left(\mathrm{WL}_{\mathrm{MODEL}} \geq-\right.$ 7.6) and low WL (WL MODEL $\leq-7.25)$. For each phase, EC was modelled against $\mathrm{WL}_{\text {MODEL }}$ and the $\triangle \mathrm{IPO}$ using multiple linear regression. The regression lines intersected at a WL MODEL of about $-7.4 \mathrm{~m}$. The final model was thus determined as:

For $\mathrm{WL}_{\mathrm{MODEL}} \leq-7.4$ :

$\mathrm{EC}_{\mathrm{MODEL}}=-5.86 \Delta \mathrm{IPO}+69.79 \mathrm{WL}_{\mathrm{MODEL}}+829$

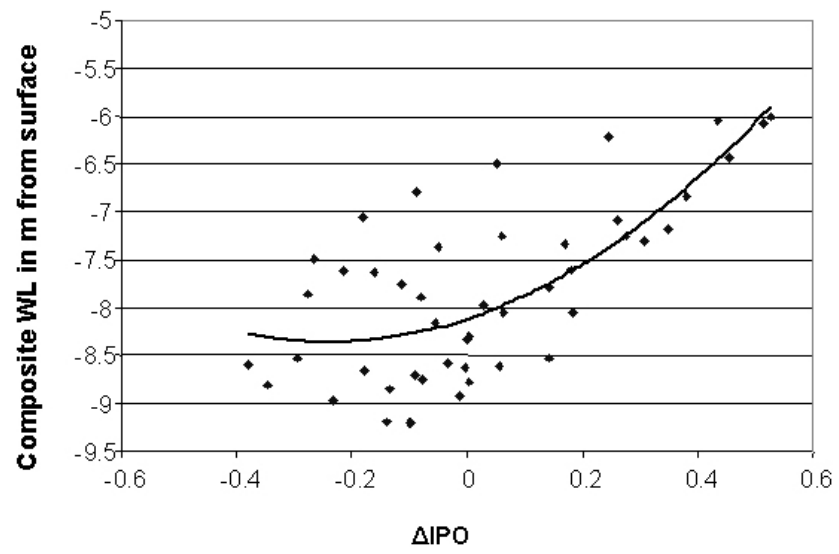

Fig. 7. Groundwater levels modelled against $\triangle \mathrm{IPO}$ using nonlinear (quadratic) regression.

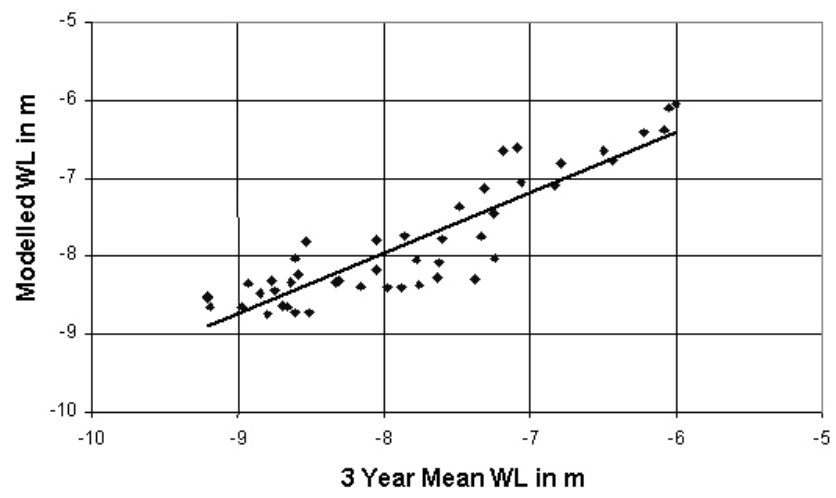

Fig. 8. Three-year moving mean groundwater levels compared with the model based on the IPO and its rate of change, $\triangle$ IPO. Correlation $R^{2}=0.81$.

For WL MODEL >-7.4:

$\mathrm{EC}_{\mathrm{MODEL}}=-106.29 \Delta \mathrm{IPO}-106.3 \mathrm{WL}_{\mathrm{MODEL}}-434$

Figure 11 shows the model fit. It has a correlation coefficient of about $75 \%\left(R^{2}=0.75\right)$ with the composite EC series. Figure 12 shows that the model reasonably reflects EC trend 


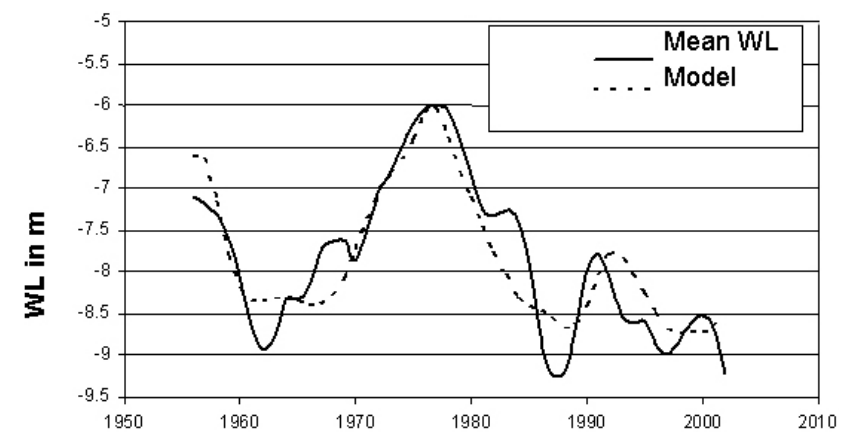

Fig. 9. Three year moving mean groundwater levels compared with the model over time, verifying a broadscale climatic component in the series. Times prior to 1968 provide a short validation period as they were not used in the model calibration.

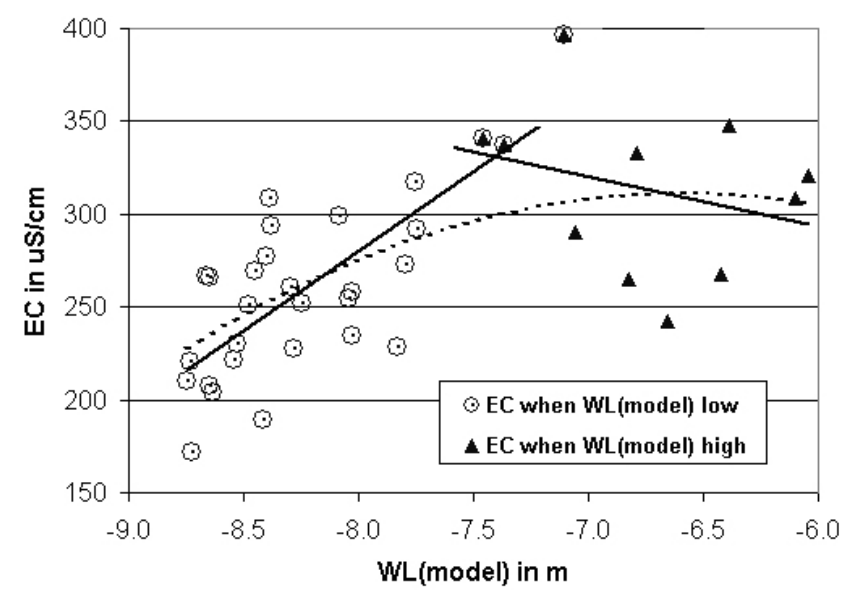

Fig. 10. EC plotted against the model of the composite groundwater level. Note the change in slope at mid water levels. Low ECs are conceptually likely to occur at both low and high water levels. The EC can be treated as one continuous nonlinear process or as two linear relationships.

directions in the years since 1968 , where the data became sufficiently representative to be included in the model calibration.

\subsection{Field evidence for the modelled climate signals}

While the records of shallow groundwater levels and stream ECs are not yet long enough to validate the calibrated models, other studies provide corroborative evidence of the occurrence of the patterns displayed in the composite series at individual sites throughout Queensland. Field evidence for the widespread decadal pattern in stream EC has already been discussed in Sect. 1.1 as displayed on Fig. 1.

For the water levels, a preliminary investigation into the occurrence of a consistent, decadal scale pattern in shallow groundwater levels, and its likely association with climate, was carried out by McNeil and Cox (2002). A total of 5680

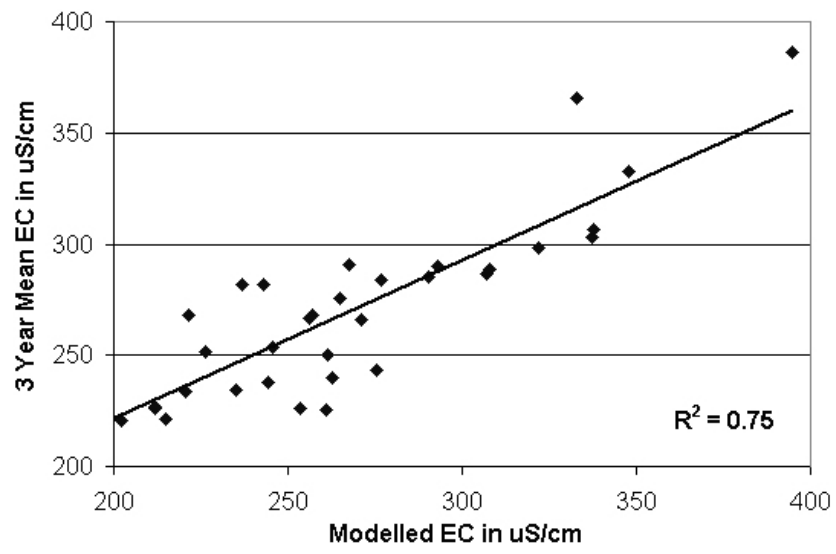

Fig. 11. Three year moving mean composite field EC compared

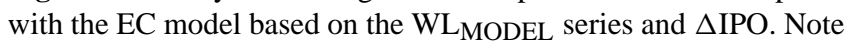
again that this model series is only intended to account for the climatic component of the variation in EC.

bores from around the state were chosen for the study because of their reasonably long and continuous water level records. The individual water level measurements for each bore were paired by date with a value from a climate control which was an early version of the $\mathrm{WL}_{\mathrm{MODEL}}$ produced for the current study. The Pearson coefficient of correlation between the WL and the control was then calculated for each bore. It was expected that the climate signal would be relatively weak in the majority of bores, due to the proximity of landuse and irrigation. Therefore a randomisation technique adapted from those discussed by Manly (1996) was employed to clarify the significance of the test. In this procedure, the correlations were repeated after randomly reallocating the water level values among the measurement dates for each bore.

Then the distributions of the correlation coefficients for each series of tests were compared. Both distributions were normal. For the correctly ordered water levels the average bore had a slight positive correlation between water levels and the climate control (median $8.5 \%$, standard deviation $38 \%$ ). On the other hand, when the data were randomly reallocated, the average correlation was zero and the spread was much narrower (median 0\%, standard deviation 11\%). Correlations greater than about $22 \%$ would almost never occur by chance in this dataset, as there were almost none in the randomised distribution. It is therefore significant that thirty percent of the correctly allocated bores were at least $30 \%$ correlated, and more than $10 \%$ were over $50 \%$ correlated. Some examples of highly correlated water level records from various parts of the state are shown on Fig. 13 from McNeil and Cox (2002). The database used in 2002 has been subsequently updated and refined through the incorporation of more representative spatial data.

Although the time series was derived predominantly from the southeast, the patterns in the series have also been found 
to be mirrored at various sites in most parts of the state, in continuance with those patterns observed in QDPI (1994). One such site was selected to trial the removal of climate trend from the EC record.

\section{The climate signal in stream salinity trends}

The main objective of the study is the separation of landuse and climate EC trends using a control series in which the climatic signal has been verified. For testing, a gauging station with a long EC history was selected in a catchment which had been extensively developed several decades ago, but where the landuse has been stable since. This was GS422316 on the Condamine River at Chinchilla, which has 117 EC readings collected between 1963 and 2004. Because field EC data is collected several times a year and is affected by season, the statewide monthly medians used to compile the composite EC series were preferred as the appropriate climate control after being smoothed by a three month moving average. Each measured EC reading was paired with this climate control value for the closest date.

\subsection{Flow correction}

Landuse affects salt transport to the stream, but most of the variability in measured EC is caused by the volume of water diluting the salt at the moment of sampling. These shortterm dilution fluctuations must be compensated for, to reveal the changes in salt concentration at a standardised flow, before determining the decadal trends reflecting landuserelated catchment processes such as increases in groundwater contribution.

Flow/EC relationships are complex and nonlinear, and are modelled using various techniques such as those proposed by, for instance, Hirsch et al. (1982), van Herpe and Troch (2000), Harned et al. (1981), Thorburn et al. (1992) and Yu and Neil (1993). The method of Thorburn et al. (1992) produces a reverse S-curve asymptotic to the EC of the groundwater during baseflow, and to that of superficial runoff during high flood. The algorithm is:

$\mathrm{EC}_{F}=\frac{\mathrm{EC}_{0}-\mathrm{EC}_{\infty}}{1+B\left(\frac{Q}{Q_{1}}\right)^{1 / m}}+\mathrm{EC}_{\infty}$

Here $\mathrm{EC}_{F}$ is the component of stream salinity variation, in $\mu \mathrm{S} / \mathrm{cm}$, attributed to streamflow effects, $\mathrm{Q}$ is streamflow, $\mathrm{EC}_{0}$ is conceptually $\mathrm{EC}$ at low flow conditions, $\mathrm{EC}_{\infty}$ is for high flows, and $B$ and $m$ are parameters to determine the curve shape in between. $Q_{1}$ is identically $1 \mathrm{~m}^{3} \mathrm{~s}^{-1}$ to keep $B$ dimensionless. In practice, $\mathrm{EC}_{0}, \mathrm{EC}_{\infty}, B$ and $m$ are all derived by robust nonlinear optimisation. The trend analysis is then carried out on the residual after flow correction, that is (EC$\left.\mathrm{EC}_{F}\right)$.

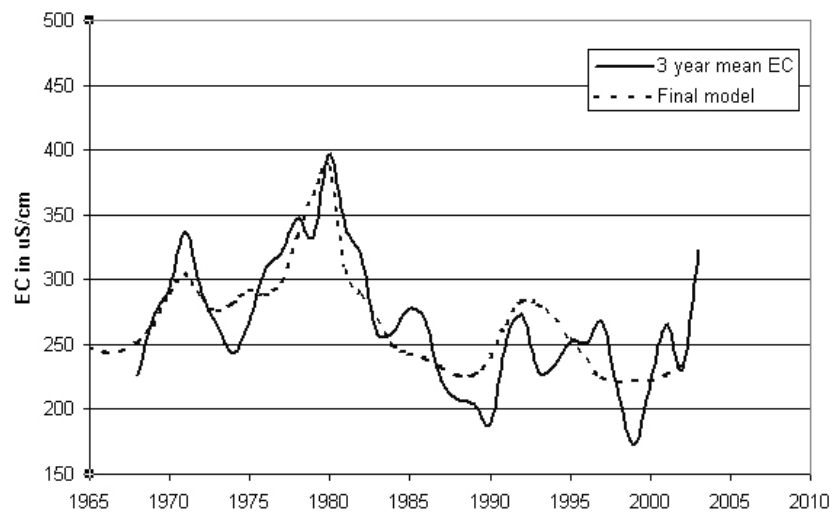

Fig. 12. Three year moving mean EC levels compared with the model over time verifying a broadscale climatic component in the series.

\subsection{Climate compensation}

A Spearman rank correlation between the Chinchilla site data and their paired monthly statewide composite ECs gave a correlation coefficient of greater than $40 \%$, corroborating the presence of a climate effect on EC at this site. A climate correction was therefore calculated for the flow-corrected monthly Chinchilla EC series, by carrying out a linear regression against the composite EC series, and taking the residuals as the new climate-compensated EC series.

\subsection{Trend calculation}

The rank based seasonal Kendall test defined by Hirsch et al. (1982), has been demonstrated to detect monotonic trends in stream EC records with unknown distributions, seasonality and missing values. The Kendall test was run first on the flow-corrected data without climate compensation. Then the same test was rerun on the flow-corrected data after climate compensation. The results are summarised on Fig. 14. Based on flow correction alone, there was a falling trend, with the null hypothesis of no trend being only $1 \%$ probable, but when the climate compensation was applied, no significant trend remained. In this case, where the landuse effect could be assumed to be negligible, the developed control series has been shown to successfully compensate for the climate signal by identifying a null landuse effect.

\section{Discussion}

The aim of this paper is to verify that there are widespread decadal scale patterns in the shallow groundwater levels and stream EC records of Queensland, and that these patterns can be accounted for by decadal scale climatic fluctuations. This has been achieved, and the patterns have been qualitatively demonstrated. 


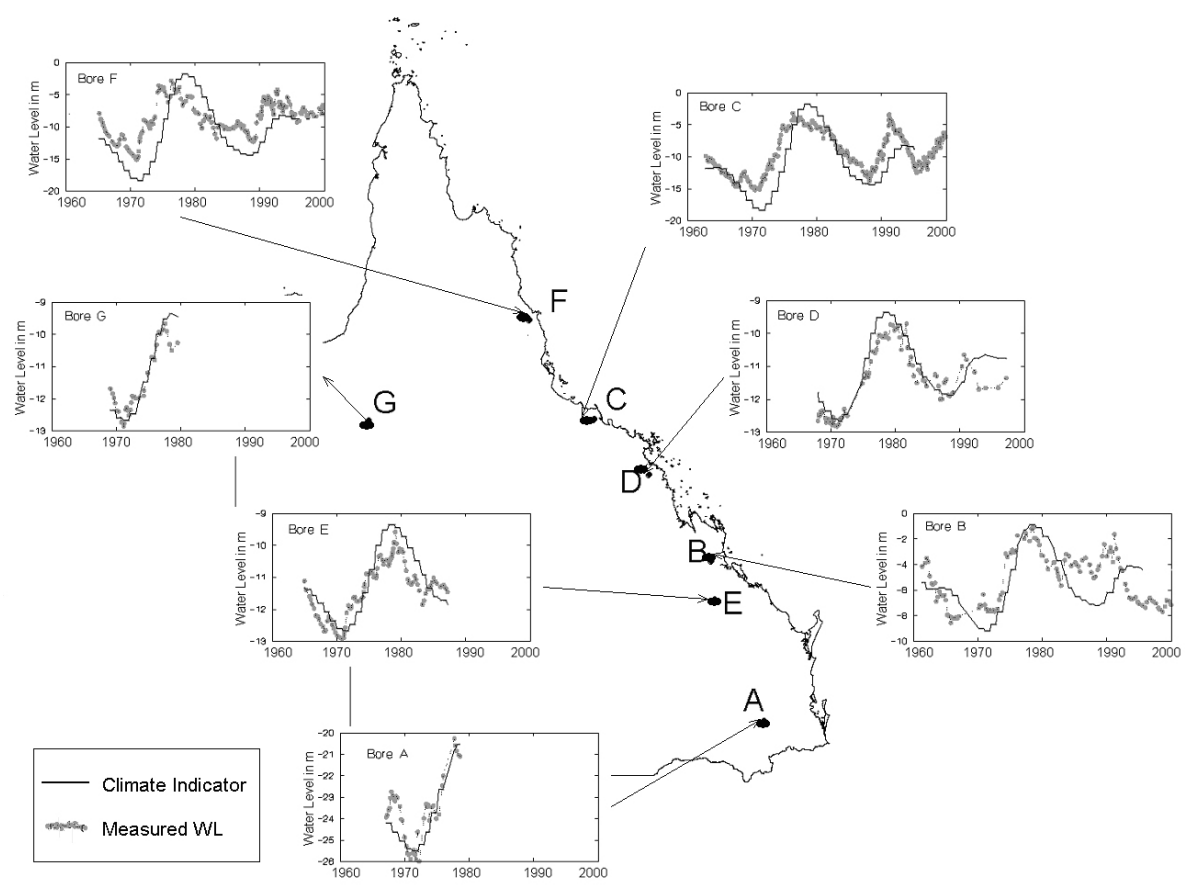

Fig. 13. Selection of bore water level records showing influence of a climatic model over a wide range of Queensland. The model curve has been scaled vertically at each site to the same spread as the measured WL.

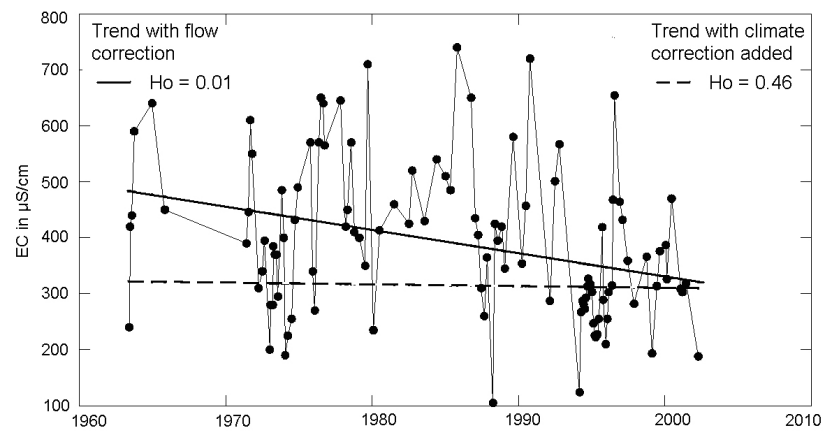

Fig. 14. EC at Chinchilla Weir. Flow-corrected Seasonal Kendall trend, with and without climate compensation. An example of a stream with an apparent falling EC trend, but with a general pattern that resembled the derived climate indicator time series. When the effect of climate was removed by linear regression with the climate indicator, no significant trend remained in the residuals.

The potential for developing a modelling tool to isolate the landuse signal from a stream EC record is also demonstrated, but full development would require more selective composite data, a better understanding of the relationship between climate and hydrological processes, and more research on the hydrological and chemical interaction at the local scale between ground and surface water in response to cumulative climate effects.

It was necessary to select a climate indicator consistent with those available in the published literature so that a cli- matic source could be demonstrated for the observed decadal patterns in the composite WL and EC series. Testing of candidate indicators identified the IPO and its derivative as the most suitable at the present time, although it is recognised that using the IPO in such a manner could be controversial. One concern is the lack of a conceptual model to relate the IPO to the hydrometeorology of Queensland. In relation to the conceptual aspects, Micevski et al. (2006), whilst acknowledging that the effects of the IPO on eastern Australian rainfall and climate are poorly understood, reviewed the literature pertaining to the reasons put forward to explain them. Some of the hypotheses put forward are summarized as follows: (1) Interdecadal sea surface temperature (SST) variations may affect convection in the equatorial Pacific Ocean leading to shifts in the rising branch of the Walker circulation, which may then influence ENSO's effect on Australian rainfall; (2) There may be increased atmospheric subsidence over Australia, i.e. lower rainfall, resulting from an anomalous regional Hadley circulation that may form above the warmer, western Pacific SSTs; and (3) Movement of the regional convergence zones such as the South Pacific Convergence Zone (SPCZ) and the Intertropical Convergence Zone (ITCZ) about their mean positions. The IPO has been shown to be associated with the location of the SPCZ in a similar manner to ENSO, but on multidecadal timescales, and it is expected that the IPO has a marked effect on the location of the ITCZ, similar to that on the SPCZ.

It is acknowledged that the IPO may not reflect a systematic process, but merely random changes in the impact of 
ENSO from decade to decade as Power et al. (2006) have suggested may be the case. However, the prevailing groundwater and stream EC levels could also be assumed to be a product of the cumulative history of ENSO as conceptualised in Fig. 2, whether these are random or structured and predictable. It is neither inferred nor required for the objectives of this study that there be a direct conceptual link between the IPO and hydrology and stream EC. It is a sufficient assumption that the patterns displayed in each may be responding to similar underlying global trends which affect decadal variability in weather patterns.

The relationship between the IPO and its derivative with the EC and WL series cannot be statistically verified at this time, because the record is very short in terms of the periodicity evident in both composite and indicator series. However, the indicators were selected through a systematic process that disclosed them as the most suitable among those trialled, which included the SOI. They proved adequate to qualitatively simulate complex decadal patterns in the composite series, which have been demonstrated to occur over a wide range of individual sites and which cannot be reasonably ascribed to any phenomena other than climate fluctuation.

The provisional use of the IPO as an indicator would therefore seem reasonable considering that it has already been applied to published hydrological studies as discussed by Verdon et al. (2004) and other authors mentioned above concerning the phases of the IPO and stream flow. Using the rate of change of the IPO rather than categorical parameters such as high/low is a rational extension of that approach. As the modelled climate control is only intended to be compared with historical records, and is not applicable to forecasting, its validity can be tested regularly against a master composite series before being applied it to individual sites.

It is accepted that more robust and better understood climatic indicators are required before reliable tools are developed to routinely extract the climate signal from slowly varying, lag responsive time series such as groundwater levels and stream EC. Extending the data set through future monitoring as well as testing of other potential indicators will lead to better understood and defined models. Because research on the climatic influences affecting groundwater and stream salinity is often limited by lack of broadscale representative data, the derived WL and EC time series are provided on http://www.hydrol-earth-syst-sci.net/11/1295/ 2007/hess-11-1295-2007-supplement.zip as supplementary material for the interest of other researchers.

\section{Conclusions}

A new approach has been demonstrated to verify the presence of the climate signal in ambient groundwater level and stream salinity records, based on the IPO and its rate of change. Although this research is in its early stages, it is evi- dent that such broadscale composite hydrological and stream salinity time series are useful for defining the medium- and long-term responses of natural systems to the climate and, by elimination, to landuse. Nevertheless, an adequate correlation between phenomena does not exclude the possibility that the apparent link may just be fortuitous random variation.

In future the control series might be refined to be more representative in space and time. Further mathematical analysis of the control series is needed to relate them more effectively to climate processes. Also, backcasting or extending the control time series, based on historical or simulated climatic variables, would help assess the full natural ranges of parameters, or the likely impacts of future climatic conditions.

Acknowledgements. We thank the Department of Natural Resources and Water, Queensland, for permission to use the water quality and groundwater databases and other unpublished reports. We recognize the collective expertise in the department and thank our many colleagues for numerous stimulating and helpful discussions, including A. McNeil and R. Clarke. We also thank S. Choy and D. Begbie for their interest and encouragement of the project and J. Salinger for providing the IPO series from the UK Met. Office.

Edited by: M. Sivapalan

\section{References}

Allan, R. J.: The Australian summer monsoon, teleconnections and flooding in the Lake Eyre Basin, Royal Geographical Society of Australia, University of Adelaide Printing Section, Adelaide, 47, 1985.

Burt, T. P. and Shahgedanova, M.: An historical record of evaporation losses since 1815 calculated using long-term observations from the Radcliffe Meteorological Station, Oxford, England, J. Hydrol., 205, 101-111, 1998.

Chiew, F. H. S., Piechota, T. C., Dracup, J. A., and McMahon, T. A.: El Nino/Southern Oscillation and Australian rainfall, streamflow and drought: Links and potential for forecasting, J. Hydrol., 204, 138-149, 1998.

Cordery, I., Yao, S. L., and Opoku-Ankomah, Y.: Forecasting drought - is it possible?, in: Hydrology and Water Resources Symposium, Newcastle, NSW, Australia, 2 July-30 June, 387391, 1993.

Evans, C., Monteith, D. T., and Harriman, R.: Long term variability in the deposition of marine ions at west coast sites in the U.K. Acid Waters Monitoring Network: impacts on surface water chemistry and significance for trend determination, Sci. Total Environ., 265, 115-129, 2001.

Folland, C. K., Parker, D. E., Colman, A. W., and Washington, R.: Large scale modes of ocean surface temperature since the late nineteenth century, in: Beyond El Nino: Decadal and interdecadal climate variability, edited by: Navarra, A., Springer, Berlin, 73-102, 1999.

Folland, C. K., Renwick, J. A., Salinger, M. J., and Mullan, A. B.: Relative influences of the Interdecadal Pacific Oscillation and 
ENSO in the South Pacific Convergence Zone, Geophys. Res. Lett., 29, 21.21-21.24, 2002a.

Folland, C. K., Salinger, M. J., Jiangand, N., and Rayner, N. A.: Trends and variations in south pacific island and ocean surface temperatures, J. Climate, 16, 2859-2874, 2002b.

Franks, S. W.: Identification of a change in climate state using regional flood data, Hydrol. Earth Syst. Sci., 6, 11-16, 2002, http://www.hydrol-earth-syst-sci.net/6/11/2002/.

Gellens, D. and Roulin, E.: Streamflow response of Belgian catchments to IPCC climate change scenarios, J. Hydrol., 210, 242258, 1998.

Gordon, N. D.: The Southern Oscillation and New Zealand weather, Mon. Wea. Rev., 114, 371-387, 1986.

Gray, W. M.: Strong association between West African rainfall and U.S. landfall of intense hurricanes, Sci. Total Environ., 249, 1251-1256, 1990.

Harned, D. A., Daniel, C. C., and Crawford, J. K.: Methods of discharge compensation as an aid to the evaluation of water quality trends, Water Resour. Res., 17, 1389-1400, 1981.

Henderson, K. A., Thompson, L. G., and Lin, P. N.: Recording of El Nino in ice core $\mathrm{d} 18 \mathrm{O}$ records from Nevado Huascaran, Peru, J. Geophys. Res., 104, 31 053-31 065, 1990.

Hirsch, R. M., Slack, J. R., and Smith, R. A.: Techniques of trend analysis for monthly water quality data, Water Resour. Res., 18, 107-121, 1982.

Hirsch, R. M. and Slack, J. A: A nonparametric test for seasonal data and seasonal dependence, Water Resour. Res., 20, 727-732, 1984.

IPCC: Report of the Intergovernmental Panel on Climate Change, edited by: Houghton, J. T., Callander, B. A., and Varney, S. K., Cambridge University Press, Cambridge, UK, 1996.

Jolly, P. B. and Chin, D. N.: Long term rainfall - recharge relationships within the Northern Territory, Australia, in: International Hydrology and Water Resources Symposium: The foundation for sustainable development, Perth, W. A., Australia, 2-4 October 1991.

Jones, K. and Everingham, Y.: Can ENSO combined with LowFrequency SST signals enhance or suppress rainfall in Australian sugar growing areas?, in: MODSIM 2005 International Congress on Modelling and Simulation, edited by: Zerger, A. and Argent, R. M., Melbourne, December, Modelling and Simulation Society of Australia and New Zealand, 1660-1666, 2005.

Kahya, E. and Dracup, J. A.: U.S. streamflow patterns in relation to the El Nino/Southern Oscillation, Water Resour. Res., 29, 24912503, 1993.

Kiem, A. S., Franks, S. W., and Kuczera, G.: Multi-decadal variability of flood risk, Geophys. Res. Lett., 30, 1035, Online access doi:1010.1029/2002GL015992, 012003.015999, 2002.

Kiem, A. S. and Franks, S. W.: Multi-decadal variability of drought risk, eastern Australia, Hydrol. Processes, 18, 2039-2050, 2004.

Loewe, F. and Radok, U.: Variability and periodicity of meteorological elements in the southern hemisphere with particular reference to Australia. Canberra, A.C.T., Commonwealth Meteorological Bureau, Meteorological Branch, Dept. of Interior, Commonwealth of Australia. 49, 1948.

Lough, J. M.: Rainfall variations in Queensland. Australia: 18911986, Int. J. Climatol., 11, 745-768, 1991.

McBean, E. A. and Rovers, F. A.: Statistical procedures for analysis of environmental monitoring data and risk assessment, Upper
Saddle River, New Jersey, Prentice Hall, 1998.

McBride, J. L. and Nicholls, N.: Seasonal relationships between Australian rainfall and the Southern Oscillation, Mon. Wea. Rev., 111, 1998-2004, 1983.

McKeon, G. M., Hall, W. B., Henry, B. K., Stone, G. S., and Watson, I. W.: Pasture degradation and recovery in Australia's rangelands: Learning from History, Queensland Department of Natural Resources, Mines and Energy, 2004.

McKerchar, A. I., Pearson, C. P., and Moss, M. E.: Prediction of summer inflows to lakes in the Southern Alps, New Zealand, J. Hydrol, 184, 175-187, 1996.

McKerchar, A. I., Pearson, C. P., and Fitzharris, B. B.: Dependency of summer lake inflows and precipitation on spring SOI, J. Hydrol., 205, 66-80, 1998.

McNeil, V. H. and Cox, M. E.: Relationships between recent climate variation and water tables on stream salinity trends in northern Australia, in: IAH International Groundwater Conference, Balancing the groundwater budget, 12-17 May, Darwin, Northern Territory, 2002.

McNeil, V. H., Cox, M. E., and Preda, M.: Assessment of chemical water types and their spatial variation using multi-stage cluster analysis, Queensland, Australia, J. Hydrol., 310, 181-200, 2005.

Manly, B. F. J.: Randomisation, bootstrap and Monte Carlo methods in biology, Chapman and Hall, London, 1997.

Micevski, T., Franks, S. W., and Kuczera, G.: Multidecadal variability in coastal eastern Australian flood data, J. Hydrol., 327(12), 219-225, 2006.

Mullan, A. B.: On the linearity and stability of Southern Oscillation-climate relationships for New Zealand, Int. J. Climatol., 15, 1365-1386, 1995.

Nicholls, N.: ENSO and rainfall variability, J. Climate, 1, 418-421, 1988.

Philander, S. G. H.: El Nino, La Nina and the Southern Oscillation. Academic Press, San Diego, 1990.

Power, S., Tseitkin, F., Torok, S., Lavery, B., Dahni, R., and McAvaney, B.: Australian temperature, Australian rainfall and the Southern Oscillation, 1910-1992: coherent variability and recent changes, Aust. Meteorol. Mag., 47, 85-101, 1998.

Power, S., Casey, T., Folland, C., Colman, A., and Mehta, V.: Interdecadal modulation of the impact of ENSO on Australia, Clim. Dyn., 15, 319-324, 1999.

Power, S., Haylock, M., Colman, R., and Wang, X.: Asymmetry in the Australian response to ENSO and the predictability of interdecadal changes in ENSO teleconnections, Bureau of Meteorology, Melbourne, Australia, 65, 2005.

Power, S., Haylock, M., Colman, R., and Wang, X.: The Predictability of Interdecadal Changes in ENSO Activity and ENSO Teleconnections, J. Climate, 19(19), 4755-4771 doi:10.1175/JCLI3868.1, 2006.

QDPI: Queensland Water Quality Atlas. Queensland Department of Primary Industries, Brisbane, 1994.

Ropelewski, C. F. and Halpert, M. S.: Global and regional scale precipitation patterns associated with the El Nino/Southern Oscillation, Mon. Wea. Rev., 115, 1606-1626, 1987.

Ropelewski, C. F. and Halpert, M. S.: Precipitation patterns associated with the high index phase of the Southern Oscillation, J. Climate, 2, 268-284, 1989.

Rowell, D. P. and Zwiers, F. W.: The global distribution of sources of atmospheric decadal variability and mechanisms over the trop- 
ical Pacific and southern North America, Clim. Dyn., 15, 751$772,1999$.

Ruprecht, J. K. and Schofield, N. J.: Effects of partial deforestation on hydrology and salinity in high salt storage landscapes, I: extensive block clearing, J. Hydrol, 129, 19-38, 1991.

Salinger, M. J., Renwick, J. A., and Mullan, A. B.: Interdecadal Pacific Oscillation and South Pacific climate, Int. J. Climatol., 21, 1705-1721, 2001.

Thorburn, P., Shaw, R., and Gordon, I.: Modelling salt transport in the landscape. In Modelling chemical transport in soils, edited by: Ghadiri, H. and Rose, C. W., CRC Pres, 180-189, 1992.

Troup, A. J.: The Southern Oscillation, Quart. J. Roy. Meteorol. Soc., 91, 490-506, 1965.

Vaccaro, J. J.: Sensitivity of groundwater recharge estimates to climate variability and change, Columbia Plateau, Washington, J. Geophys. Res., 97, 2821-2833, 1993. van Herpe, Y. and Troch, P. A.: Spatial and temporal variations in nitrate concentrations in a mixed land use catchment under humid temperate climatic conditions, Hydrol. Processes, 14, 24392455, 2000.

Verdon, D. C., Wyatt, A. M., Kiem, A. S., and Franks, S. W.: Multidecadal variability of rainfall and streamflow: Eastern Australia, Water Resour. Res., 40, W10201, doi:10.1029/2004WR003234, 2004.

Yu, B. and Neil, D. T.: Salinity trend of the Williams River, Western Australia, J. Roy. Soc. Western Australia, 76, 71-76, 1993.

Zhang, Y., Wallace, J. M., and Battisti, D. S.: ENSO-like interdecadal variability: 1900-93, J. Climate, 10, 1004-1020, 1997.

Zorn, M. H. and Waylen, P. R.: Seasonal response of mean monthly streamflow to El Nino/Southern Oscillation in North Central Florida, Prof. Geogr., 49, 51-62, 1997. 